\title{
Q method to map the diversity of stakeholder viewpoints along agricultural innovation systems: a case study on cattle genetic improvement in Niger
}

\author{
Seyni Siddo ${ }^{1,2}$, Nassim Moula ${ }^{1}$, Issa Hamadou ${ }^{1,2}$, Moumouni Issa $^{3}$, Salissou Issa ${ }^{1}$, Marichatou Hamani ${ }^{3}$, \\ Pascal Leroy ${ }^{1}$, and Nicolas Antoine-Moussiaux ${ }^{1}$ \\ ${ }^{1}$ Fundamental and Applied Research for Animals and Health (FARAH), Faculty of Veterinary Medicine, \\ University of Liege, avenue de Cureghem, 6, 4000 Liege, Belgium \\ ${ }^{2}$ National Institute of Agronomic Research of Niger, P.O. Box 429 Niamey, Niger \\ ${ }^{3}$ Faculty of Agronomy, University Abdou Moumouni, P.O. Box 10960 Niamey, Niger
}

Correspondence: Nicolas Antoine-Moussiaux (nantoine@uliege.be)

Received: 4 December 2017 - Revised: 13 February 2018 - Accepted: 28 February 2018 - Published: 27 March 2018

\begin{abstract}
The complex balance between innovation and conservation regarding animal genetic resources makes it difficult to find mutually accepted improvement pathways between breeders, government agencies, and research and education institutions. This study maps stakeholder viewpoints on cattle genetic improvement in Niger using the Q method. Fifty-three statements derived from expert opinions and focus group interviews were ranked by 22 respondents along a seven-grade scale expressing their degree of approval. The $\mathrm{Q}$ method reveals a limited consensus on development goals, overall strategy, and the present context of operation. Beyond this consensus, three discourses are identified that express distinct attitudes regarding the balance between conservation and progress, leading to distinct strategies. The first discourse fits with a modernist vision and government strategies established in the 2000s based on exotic crossbreeding and improved purebred Azawak. The second discourse lines up with the previous livestock development strategy of Niger (before 2000) based on indigenous breeds. The third discourse represents a conservationist vision, with minor importance in the present sampling. Tentative observations are proposed on the consequences of this divide in opinions on livestock policies in Niger, including extension. The Q method appears effective in identifying the concerns of stakeholders on complex agricultural innovation topics. As a sensing tool to follow-up policy implementation in similarly complex agricultural topics, the Q method may inform adaptive extension and education strategies.
\end{abstract}

1

Agricultural innovation systems (AISs) provide a holistic framework to analyze technical and institutional changes in agriculture (Klerkx et al., 2012). This approach is an attempt to acknowledge and take account of the complexity of innovation processes. By avoiding a sterile holism, the complexity framework itself invites practical management options (Cilliers et al., 2013). These include the need to harness the diversity of actor values and expectations, to stimulate social learning systems (Wenger, 2010), and to implement sensitive qualitative follow-up methods in the "scanning" and "sensing" of changes in addition to measurable outcomes (Cilliers et al., 2013). Many qualitative research tools have been developed to identify values and opinions framed around a given topic in a community (Ndahi et al., 2012; Shiferaw et al., 2010). The Q method is one of those tools that applies statistical tools in a strictly qualitative approach and characterizes different viewpoints or prevailing discourses in a specific area. This tool has been used in many studies, including policy evaluation, decision-making, and various participatory processes (for a nonagricultural example, see Shabila et al., 2014).

Among agricultural development issues, animal genetic resource (AnGR) management is a difficult problem seeking to embody the balance between progress and conser- 
vation. Indeed, genetic improvement, more than a technical fact, is a societal enterprise, which therefore requires the participation of all stakeholders in order to achieve efficiency and durability (Leroy et al., 2017). Thus, there is first a need to ensure the adequacy of this genetic progress with the breeding environment, including socioeconomic and cultural characteristics, institutional and infrastructural framework, and preferences of breeders. This adequacy has often raised challenges in developing countries where animal breeding programs have known many failures (Madalena et al., 2002; Kosgey et al., 2006; Rege et al., 2011; Leroy et al., 2015). Driven by the need to think about system sustainability under uncertainty, AnGR management generates divergent opinions and practices, depending on actor values and expectations (Hamadou et al., 2016). Indigenous livestock breeds, providing a crucial livelihood to people throughout the world, are presently under threat (FAO, 2015). The diversity of adaptive traits, sometimes to particularly harsh environmental conditions such as those in Sahelian Africa, is key in the sustainable exploitation of fragile ecosystems (Leroy et al., 2015). Market globalization, along with easing the exports of animals, animal products, and semen from industrialized and emerging countries to developing countries, has resulted in a rapid loss of indigenous breeds and their gradual replacement by exotic breeds or their crossbreeds (Tisdell, 2003). Therefore, animal genetic improvement is an important issue for AIS analysis in a complexity framework as described above. A first approach to actor diversity inside the AIS is thus proposed here through the application of the Q method.

As with any approach to complexity, the $\mathrm{Q}$ method requires a purposeful framing decision delineating the problem boundaries in agreement with the objective of the system analysis (Cilliers et al., 2013). Recently, Pereira et al. (2016) applied the Q method in the framework of AIS by targeting a specific subset of actors, i.e., farmers previously identified as exhibiting a progressive attitude. Hamadou et al. (2016) adopted the opposite framing strategy in a Q method application to indigenous breed conservation, including a wide array of stakeholders from farmers to policy makers. This approach advocates that, to be effective and sustainable, AnGR management policies need to be formulated and implemented with the active involvement of all stakeholders, promoting good communication between them. Fitting into this same proposition, the present $\mathrm{Q}$ method applies a wide framing of actors involved along the AIS governing animal genetic progress. It addresses the issue of cattle improvement in the context of the Niamey region, Niger.

In Niger, five native cattle breeds are exploited with a total of 11 million head. These are four indigenous zebu breeds (Azawak, Bororo, Djelli, and Goudali), which are distributed throughout the country, and one taurine breed, the Kouri, limited to a small portion of the Diffa region at the edge of Lake Chad. Like in other Sahelian countries, three farming systems are utilized in Niger: pastoralism, sedentary live- stock farming in association with agriculture, and suburban livestock farming. The first two are considered as lowinput systems, while the suburban system is described as semi-intensive, benefiting from the support of development projects and proximity to markets (imported animal feed from Benin, Burkina Faso, and Nigeria; MRA, 2003). The positioning of livestock improvement policies in Niger has experienced an important change in its recent history. Indeed, the promotion of indigenous breed diversity has been a dominant paradigm for decades. In 2000, a drastic change occurred with the introduction of exotic crossbreeding as an official strategy (Cristofori et al., 2005; Issa et al., 2013). Innovative actors mixed both strategies, illustrating the complexity of AIS evolution. This study applies the Q method with a set of respondents selected along the innovation system to derive the main discourses at play in Niger about cattle improvement. It aims to illustrate the practical usefulness of the $\mathrm{Q}$ method as a qualitative evaluation tool for policy implementation. The mapping of actor viewpoints is intended here as a first step to feed into a wider strategy to "scan" and "sense" the changes in the system along its future evolution.

\section{Materials and methods}

\subsection{Overall description of the $Q$ method}

The Q method identifies the patterns of subjective perspectives held by a group of interviewees on social issues (Lazard et al., 2011). It is a qualitative exploratory technique that uses multivariate statistical tools for the rigorous analysis of similarities across individual opinions (Lazard et al., 2011). As a qualitative method, it does not allow for and does not aim at inference or transfer to larger populations. The interviewees are not sampled for representativity but are chosen on the basis of their roles in the issue considered and the expected diversity of opinions.

\subsection{Construction of the statements list ( $Q$ sample)}

First, a selection of discourses on the topic of animal genetic improvement in the tropics was developed (Van Exel and De Graaf, 2005). The Q sample, i.e., the list of statements to be scored by respondents, was established based on a literature review, including national policy statements and three preliminary focus group discussions with field actors: breeders, animal production technicians, and researchers. The clarity of the statements was tested and improved with five cattle breeders and five technicians from the Ministry of Livestock. Finally, 53 statements were established covering objectives, constraints, and means of cattle genetic improvement in Niger. 


\subsection{Sampling of respondents (P set)}

The purposive P-set sampling included 22 respondents in Niamey and its vicinity. The different professions included were researchers in animal production (from the National Agricultural Research Institute and the University of $\mathrm{Ni}$ amey; $n=2$ ), economists (from the National Agricultural Research Institute; $n=2$ ), genetic improvement specialists from the Ministry of Livestock $(n=4)$, extension agents (from rural and suburban areas; $n=4$ ), development project agents (national and foreign personnel; $n=4$ ), and breeders, i.e., animal owners $(n=2)$, herders $(n=2)$, and the leaders of peasant associations $(n=2)$. Hence, suburban livestock farming was included, with both extensive and intensive sedentary rearing practices, as well as rural breeding contexts, characterized by crop-livestock integration and herd mobility.

\section{Data collection}

The data were collected from March to April 2014 through face-to-face interviews. The study aim, rules for information disclosure (guarantee of anonymity and use of only profession information in the data analysis and presentation), and the voluntary basis of participation were expressed to each interviewee before obtaining their consent. The list of statements was presented together with a seven-grade scale: I totally disagree $(-3)$, I disagree $(-2)$, I do not really agree $(-1)$, I am neutral ( 0$)$, I fairly agree $(+1)$, I agree $(+2)$, I fully agree $(+3)$. This grid was selected to reduce task complexity, as decided on the basis of preliminary tests. The respondents were asked to carefully read the whole list of statements and then to ascribe a grade to each statement according to their level of agreement. The list of graded statements for one interviewee is termed the Q sort. Allowing for the free allocation of scores also reduced task complexity by avoiding forced distributions but still asking the respondents to score each statement relative to others. The forced distribution of $\mathrm{Q}$ sorts is practical in terms of provoking neat results, but may be overlooked without affecting the analysis outcome (Van Exel and De Graaf, 2005).

After the interviews, open questions addressed respondent perceptions of the procedure and asked for precision regarding the chosen scores and answers given.

\section{Data analysis}

Q sorts were analyzed through principal component analysis (PCA) with varimax rotation using the ad-hoc package qmethod (Zabala, 2014) with R software 3.0.1 (R Development team, 2015). The full details of the data analysis strategy can be found in the paper of Hamadou et al. (2016). The number of factors retained for data description was chosen on the basis of the extent to which these were associated with recognizable positions in the genetic improvement debate, while representing more than one Q sort. Each Q sort was ascribed to one of the factors through an automatic flagging ( $q$ flag function) based on the correlations between the $\mathrm{Q}$ sort and the factor (factor loadings). The mean and distribution of the scores of one statement in the Q sorts ascribed to one factor indicate the position of this factor regarding this statement (z score function). Comparisons between these distributions among factors allow for the identification of statements along three modalities: consensual, (i.e., showing no statistical difference between factors), distinguishing (i.e., showing a statistical difference between two or more factors), and nonstructuring (i.e., showing a statistically nonsignificant difference with a wide diversity of opinions among all factors; Zabala, 2014). Distinguishing statements with strong grades $(+3,+2,-2,-3)$ are mobilized in priority for the qualitative analysis of opinions (Shabila et al., 2014).

\section{Results}

\subsection{Overall description of statistical results}

Three factors were retained for a total share of explained variance of $48.8 \%$. After varimax rotation, the percentages of variation represented by these three factors were 20.1, 20.1, and $8.6 \%$. Their composite reliability was $0.97,0.98$, and 0.89 .

\subsection{Consensus and nonstructuring statements}

Consensus and nonstructuring statements are presented in Table 1. A strong consensual agreement is observed on the need for improved milk production (statement 1), the role of family farming in increasing production (statement 5), and the need for Azawak zebu promotion (statement 8). A consensus is also observed on the preferential use of natural mating for improved breed dissemination (statement 16), although with weaker agreement compared to previous statements, while the statement about the usefulness of AI is nonstructuring (statement 18). Meat prices are consensually considered favorable to the creation of intensive production systems (statement 20), contrary to the cattle feed price (although the latter statement appeared to be nonstructuring; statement 22). A consensus appeared regarding the institutional framing of the livestock sector, which is deemed unfavorable, with insufficient investments of the government in indigenous breed production (statement 43) and a neutral response on the availability and reliability of veterinary services (statement 23).

\subsection{Factor description: main discourses and perspectives}

Statements distinguishing all three factors are presented in Table 2 and those distinguishing only one factor from the two 
Table 1. Consensus and nonstructuring statements.

\begin{tabular}{|c|c|c|c|c|}
\hline \multirow[b]{2}{*}{ No. } & \multirow[b]{2}{*}{ Statements } & \multicolumn{3}{|c|}{ Q-sort scores } \\
\hline & & f1 & $\mathrm{f} 2$ & f3 \\
\hline & Consensus statements & & & \\
\hline 1 & It is important for Niger to increase milk production & 3 & 3 & 3 \\
\hline 5 & Small family farms will be important to increase national production & 3 & 3 & 3 \\
\hline 8 & Breeding pure Azawak from Toukounous should be promoted & 3 & 3 & 2 \\
\hline 16 & Genetic improvement using bulls for natural mating is favorable in Niger & 1 & 1 & 2 \\
\hline 20 & The present meat price is favorable for new investments in modern farms & 1 & 2 & 1 \\
\hline 23 & Public veterinary services are available and reliable & 0 & 0 & -1 \\
\hline \multirow[t]{2}{*}{43} & Government investments for farmers rearing indigenous cattle are adequate & -2 & -2 & -3 \\
\hline & Nonstructuring statements & & & \\
\hline 12 & To increase meat production, crossbreeding exotic bulls with indigenous cows should be promoted & 2 & 1 & 1 \\
\hline 18 & Genetic improvement by artificial insemination with indigenous breed seeds is favorable in Niger & 1 & 2 & 2 \\
\hline 22 & The cattle feed price is reasonable & -3 & -3 & -2 \\
\hline 44 & Improved livestock breeders have made additional investments in recent years & 2 & 0 & 0 \\
\hline 49 & The policy to promote the breeding of indigenous cattle is satisfactory in Niger & -2 & -1 & 0 \\
\hline
\end{tabular}

The Q-sort score is the relative importance that the participants place on a particular discourse in the individual statements: the more positive a number, the more important the statement for this discourse and vice versa; $\mathrm{f} 1, \mathrm{f} 2$, and $\mathrm{f} 3$ stand for discourse 1,2 , and 3 .

others are shown in Table 3. These distinguishing statements allow for the interpretation of factors as distinct discourses.

\subsubsection{Discourse 1: perspective of livestock sector modernization and exotic germplasm use}

Discourse 1 is the one most in favor of a "modern" view of genetic improvement, with the dissemination of exotic breeds and improved purebred Azawak (statements 7, 9, 10). Nine respondents (of 22) are associated with this discourse, belonging to different categories in the $\mathrm{P}$ set and including researchers, extension services, genetic improvement specialists from the Niger Ministry of Livestock, and development project agents. This discourse is the only one to disagree with the possibility of developing a livestock sector based on indigenous breeds only (statement 15). It is further in favor of ranching (statement 39) and commercial farms (statement 6). This discourse is the only one to agree, although moderately, with the sustainability of the rearing of "improved cattle" (i.e., exotic crossbred or purebred) in Niger (statement 34). This discourse is the most strongly dissatisfied regarding the present training level of breeders in husbandry techniques (statements 30,31,32) and the promotion policies for exotic cattle (statement 50).

\subsubsection{Discourse 2: perspective of adapted modernization based on indigenous Azawak cattle}

Discourse 2 reflects the perspective of 11 respondents of 22, i.e., breeders (animal owners, herders, and peasant association leaders) and economists. This discourse is the only one not agreeing with giving milk production priority over meat production (statement 3 ). To increase meat production, discourse 2 would promote the crossbreeding of Azawak purebred bulls from the Toukounous breeding station with all indigenous cattle breeds (statement 13), but it does not advocate the direct use of these purebred improved Azawak on farms (statement 11 and 14). It shows a distinctive disagreement with the accessibility of Toukounous station Azawak; these animals are considered too expensive (statement 41) and not readily available (statement 46). This discourse proves rather neutral about satisfaction with the training level of breeders on rearing techniques for cattle in general and for improved Azawak (statements 30 and 31). It is also significantly less dissatisfied, compared to discourses 1 and 3, with the level of training on the rearing of exotic and crossbred cattle (statement 32).

Discourse 2 shows the strongest agreement with the necessity of modernizing cattle breeding in Niger (statement 39) and it is the only one indicating that the creation of ranches or commercial farms in Niger would be easy (statement 40); this is supported by favorable milk prices (statement 19). Discourse 2 encourages the development of a policy promoting improved cattle in Niger (statement 48) and indicates a lack of funds for breeders themselves to invest in this improvement (statement 36), thus rendering them unwilling to pay for artificial insemination (statement 35).

\subsubsection{Discourse 3: perspective of strictly endogenous progress}

The third discourse is shared by only two respondents of the total, i.e., development project agents (a foreign aid actor and a milk processing company manager). It is characterized by 
Table 2. Statements distinguishing all three discourses.

\begin{tabular}{|c|c|c|c|c|}
\hline \multirow[b]{2}{*}{ No. } & \multirow[b]{2}{*}{ Statements } & \multicolumn{3}{|c|}{ Q-sort scores } \\
\hline & & f1 & $\mathrm{f} 2$ & f3 \\
\hline 3 & For Niger, milk production is a priority compared to meat production & 2 & -1 & 3 \\
\hline 6 & Commercial livestock farms will be important to increase national production & 2 & 1 & -1 \\
\hline 7 & Crossbreeding exotic bulls with indigenous cows should be promoted & 3 & 2 & -2 \\
\hline 9 & To increase milk production, crossbreeding exotic bulls with indigenous cows should be promoted & 3 & 2 & 0 \\
\hline 10 & $\begin{array}{l}\text { To increase milk production, crossbreeding Azawak bulls with indigenous cows (of all breeds) should be } \\
\text { promoted }\end{array}$ & 3 & 1 & -1 \\
\hline 11 & To increase milk production, breeding pure (with sires Azawak from Toukounous) should be promoted & -2 & -1 & 2 \\
\hline 14 & To increase meat production, breeding pure (with sires Azawak from Toukounous) should be promoted & -2 & -3 & 3 \\
\hline 15 & It is possible to improve the national production of livestock products based on indigenous breeds only & -1 & 1 & 3 \\
\hline 24 & Private veterinary services are available and reliable & -1 & -3 & 2 \\
\hline 25 & The prices of veterinary services are reasonable & 1 & -1 & 3 \\
\hline 26 & Environmental and health conditions in Niger are favorable to rear indigenous cattle & -1 & 3 & 3 \\
\hline 29 & Environmental and health conditions in Niger are favorable to rear crossbred cattle & 0 & 1 & -3 \\
\hline 34 & Improved livestock breeding (in general) is viable in rural areas & 1 & 0 & -3 \\
\hline 35 & Breeders are willing to pay artificial insemination costs & 0 & -3 & 2 \\
\hline 39 & $\begin{array}{l}\text { Animal husbandry modernization by establishing ranches or farms is necessary for livestock development in } \\
\text { Niger }\end{array}$ & 2 & 3 & -2 \\
\hline 48 & A policy to promote the breeding of improved cattle is necessary in Niger & 3 & 2 & 1 \\
\hline
\end{tabular}

The Q-sort score is the relative importance that the participants place on a particular discourse in the individual statements: the more positive a number, the more important the statement for this discourse and vice versa; $\mathrm{f} 1, \mathrm{f} 2$, and $\mathrm{f} 3$ stand for discourse 1,2 , and 3.

an overall rejection of the use of exotic crossbreeding in both rural and peri-urban areas (statements 7, 17, 29, 33, 34, 37). The use of purebred Azawak is considered as more favorable (statements 11 and 14), but the unwillingness to use Azawak crossbreeding with other indigenous breeds (statement 10) stresses an overall concern for AnGR conservation. For this discourse, environmental conditions are not appropriate for the management of improved breeds (statement 29). It promotes the development of animal production based on indigenous breeds (statement 15) to fit into the local climatic and institutional constraints (statements 26, 29, and 53). The opinion on the level of training of breeders is in line with this judgment in favor of indigenous breeds, i.e., respondents are satisfied with the training level on rearing techniques for cattle in general (statement 30), neutral about the case of improved Azawak (statement 31), and strongly dissatisfied regarding the case of exotic and crossbred cattle (statement 32).

\section{Discussion}

The Q method was successful in providing an overall description of the main opinions of the different stakeholders on cattle genetic improvement in Niger. Notwithstanding its use of quantitative statistical tools, the Q method is fundamentally qualitative by nature. It is proposed here as a tool to sense the evolution of an innovation system, with the explicit goal of taking the diversity of viewpoints into account as a crucial component of the management strategy in a context marked by complexity (Cilliers et al., 2013). In accor- dance with this objective, this discussion will build on the discourses to develop a practical way forward.

Although consensus statements are relatively few (7 statements of 53), they describe the common basis to which past policies and messages have contributed and on which future policies may be built. The consensual acknowledgment of the need to increase milk production and the role of family farming and Azawak zebu in this regard appears as a strong basis for action, which is in line with the past and present strategies of the country (Vias, 2013). Other consensual statements relate to the context analysis, with a negative perception of the institutional framework for cattle breeding, particularly regarding public investments directed towards indigenous breeds. Another element of consensus pertains to the means of genetic improvement, with a shared preference for natural mating. Hence, the first steps should be based on this widely accepted idea of natural mating and then gradually build trust in artificial insemination services. The setting up of artificial insemination services is, indeed, a crucial challenge in developing countries as Niger due to long distances, poor infrastructure, lack of farmer knowledge, and poor acceptability of the technique (Madan, 2005). Let us recall here that artificial insemination, if used to spread crossbreeding with exotic breeds, may increase the speed of AnGR erosion. Therefore, it must be part of a wider AnGR management strategy shared by the various stakeholders and subject to a close follow-up of its consequences.

Alongside this consensus, the three discourses defined may be considered as quite clear-cut opinions correspond- 
Table 3. Statements clearly distinguishing each factor from the rest.

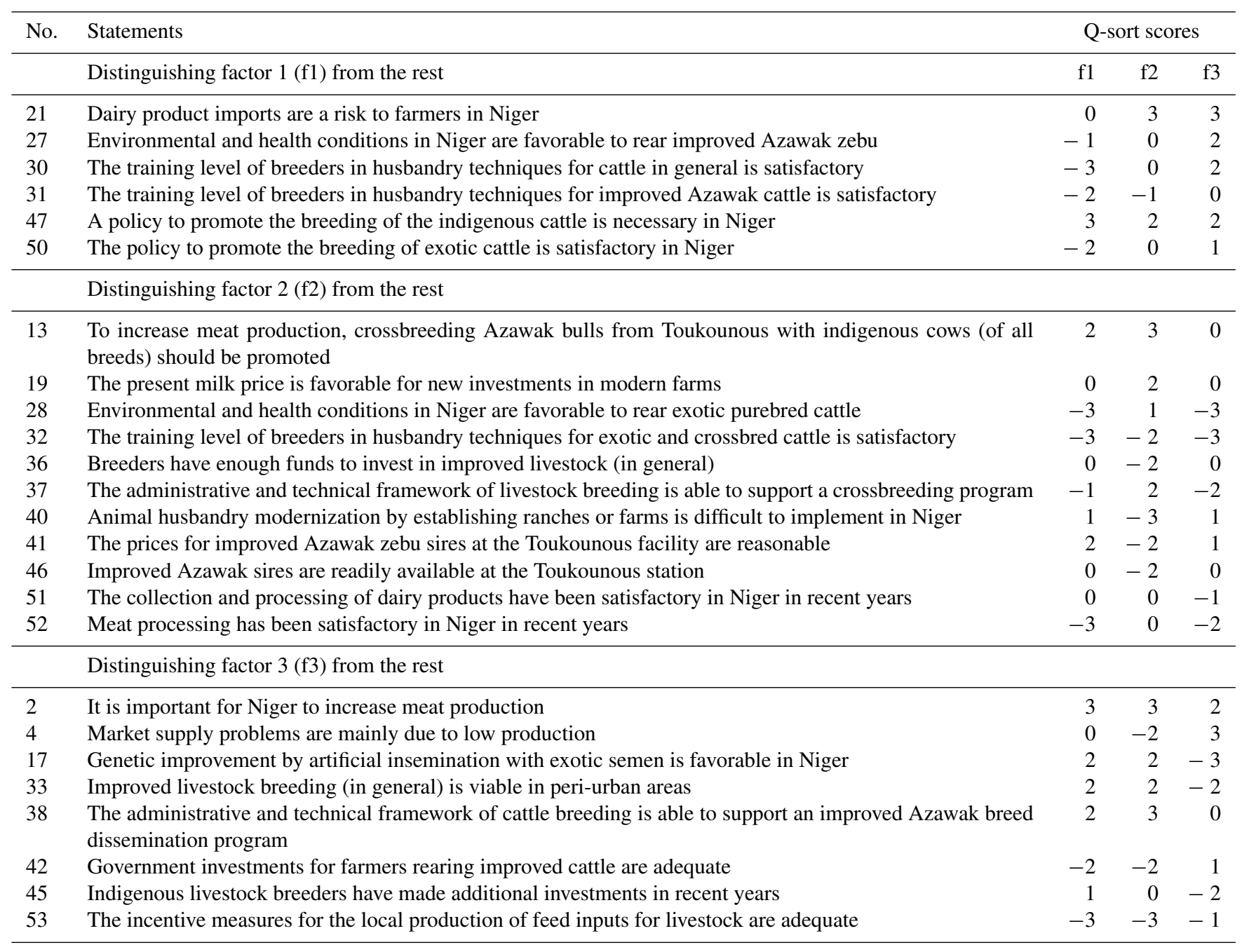

The Q-sort score is the relative importance that the participants place on a particular discourse in the individual statements: the more positive a number, the more important the statement for this discourse and vice versa; $\mathrm{f} 1, \mathrm{f} 2$, and $\mathrm{f} 3$ stand for discourse 1,2 , and 3.

ing to (i) livestock modernization open to exotic germplasm, (ii) conditional and adapted modernization based on the dissemination of Azawak zebu, and (iii) strictly endogenous progress with breed conservation concerns. Although once obtained such a division may seem expected, it nonetheless provides thoughtful insights into the present stakes involved in Niger cattle genetic improvement policies.

First, the broad agreement between the first and second discourses around the concept of modernization shows that, for future policies, messages framed around this willingness would gain a wide acceptance. The quite minor importance in the present $\mathrm{P}$ set of the third conservationist discourse, however, highlights the need for caution regarding AnGR management through the process of sector development, which is a dimension that is also present in a more nuanced way in the second discourse.
Second, the profiles of the sampled interviewees bearing different opinions may also lead to practical observations. In agreement with the $\mathrm{Q}$ method qualitative nature, these observations are made without a claim for representativity and should rather be considered as hypotheses to be tested through further quantitative surveys. Also, this study undertakes an analysis at the level of the multi-stakeholder system. This inevitably leads to a loss in the diversity of actors within categories due to the overall limitation of the number of interviewees allowed by the methodology. Therefore, one might consider it relevant to investigate each of the proposed observations within a set of interviewees focusing on one role in the system. Within these possibilities, a closer view on the diversity of opinions among different farmer types would be of particular interest.

Indeed, the first discourse promoting exotic germplasm is given by agents directly related to state policy. As such, 
their discourse is in agreement with the national strategy defined in 2000 to cover national demand and integrate international markets (MRA, 2001) and the 2012-2020 action plan of the Ministry of Livestock for the intensification of animal production (SDDE, 2013). According to this view, breeders are considered as poorly performing professionals who require top-down training and extension policies. Such policies are commonly implemented in developing countries, with an increase in exotic genetic material imports (BiberKlemm and Temmerman, 2011). Interestingly, the socioeconomists among our sample expressed unfavorable views regarding this policy and fit into the second discourse with all of the sampled breeders. Hence, these sampled actors share the same vision of the trade-off to be sought between the need for progress and the caution implied by the constrained operational context. This caution regarding exotic germplasm imports is explained by issues surrounding the adaption of highly productive European breeds to environmental conditions in Niger. A lack of adaptation entails high economic risks for the farmer and has contributed to the failure of crossbreeding programs in other developing countries (Madalena et al., 2002; Leroy et al., 2016), resulting in large economic losses for small producers due to the high maintenance needs of crossbreeds, their weak performance under extensive systems, and their higher susceptibility to diseases or adverse climate conditions (e.g., Demeker et al., 2004). As a result, a weakly framed exotic breed introduction has the potential to lead to a rapid loss in adaptability options for traditional livestock systems (Karugia et al., 2001). Nevertheless, the second discourse does not explicitly stress the inadequacy of environmental conditions in Niger for exotic crossbred cattle (statement 29), which is in fact only proposed by the third conservationist discourse. Rather, it presents a positive expression of this question, affirming the good adaptation of indigenous cattle.

The second discourse seems to line up with the past strategy for livestock development in Niger, which was mainly based until 2000 on indigenous cattle breeds (MRA, 2001). This policy was at odds with those of other West African countries. The Niger strategy was at that time based on the promotion of ranching exploiting indigenous breeds such as Azawak and Bororo zebus or Kuri taurine cattle (MRA, 2001). In post-questionnaire open interviews, several livestock producers stressed the fact that raising exotic crossbreeds requires investments that they cannot afford. Therefore, this study indicates a weak ownership among breeders regarding the present crossbreeding strategy, while the past strategy had reached the desired overall acceptance of these stakeholders.

Problems in traditional livestock farms are not intrinsically low meat or milk production as these systems also have low investments regarding equipment, feed, and healthcare (Madan, 2005; Scholtz et al., 2011). Also, the indigenous genetic make-up does not allow for a complete shift to intensive systems as a profitable venture (Yigrem et al., 2008).
Therefore, at the present stage of livestock sector development in Niger, balanced feed supplements and veterinary services in a system based on indigenous breeds and natural pastures may bring the needed increase in production in a way that farmers can afford, while avoiding the risks tied to exotic germplasm introduction. Such an introduction would be strictly managed on duly equipped premises with good access to veterinary care.

Although these preliminary observations call for deeper and more quantitative approaches to perceptions and attitudes, it points to divides between disciplines (animal production vs. economics) and actor categories (extension agents vs. breeders) and highlights the challenge of both interdisciplinary and participatory approaches in agricultural research and policy making. It was incidentally noted that actors from development projects are divided between the two rigorously opposite perspectives, i.e., discourses 1 and 3 . To evaluate these divides and the resulting influences on the country's policy, the present results could be used to elaborate short questionnaires that are able to target perceptions and attitudes towards the critical statements analyzed here.

The perceived need for extension across this divide is of particular interest. Through the statements on satisfaction about technical training levels regarding cattle in general and improved Azawak and exotic or crossbred cattle, the study points to a very critical assessment by discourse 1 (held by extension agents and public services), while discourse 2 (held in our sample by breeders and economists) is more neutral on the subject. Interestingly, the conservationist discourse 3 also states a dissatisfaction regarding the training level of breeders, especially for the rearing of exotic or crossbred cattle. This could be interpreted as pointing to a conviction that these animals are not adapted to the context rather than to a need for training to allow for their introduction, as would be derived from the modernist discourse 1 . This study tends to show that distinct demands or expectations regarding agricultural extension emerge from differences in opinions on the wider project of production, putting up potential barriers to extension efficacy. Embarking with stakeholder perception onboard when building an extension strategy is needed to promote their participation and hence the efficacy of the strategy (McDonough et al., 2015). However, in addition to technical competence, agricultural extension or education improves the communicational and leadership competence of farmers in the innovation process, thereby facilitating multi-stakeholder exchanges and collective decisionmaking (World Bank, 2012; Halbleib and Jepson, 2015). Therefore, this difference in expectations deserves a more targeted investigation to understand the pathways towards a more congruent vision among stakeholders, at least about the needs that are common to all strategies, to allow for further dialogue. 


\section{Conclusions}

Beyond the particular case of Niger, this paper proposes the $\mathrm{Q}$ method as a valuable tool in the management of complex multi-actor problems as encountered in animal breeding. The many trade-offs constituting the setting up of a policy on animal genetic improvement and genetic resource management can result in several opinions that may develop and enter into conflict. This diversity of opinions needs to be characterized to inform policy making and monitoring. In particular, the present results suggest that stakeholder opinions may be influenced by past policies and that this may then influence the reaction of the system to new policies. As a readily applicable protocol for viewpoint mapping, the Q method may be applied at different time points among stakeholders in the same system to assess this dialogue by highlighting the evolutions in main discourse patterns and hence the impact of extension strategies on actor attitude, perception, and awareness. This appears strategic in animal breeding policies, which need both a continuous effort in the long run and the deep involvement of all stakeholders in order to be effective and sustainable.

Data availability. Any interest in accessing the data should be directed to the authors.

Competing interests. The authors declare that they have no conflict of interest.

Acknowledgements. The authors are grateful to the Belgian Technical Cooperation Agency and the Development Cooperation Commission of the Académie de Recherche et Enseignement Supérieur (ARES-CCD) for their support to Seyni Siddo.

Edited by: Steffen Maak

Reviewed by: Gregoire Leroy and Philipp Muth

\section{References}

Biber-Klemm, S. and Temmerman, M.: Rights to animal genetic resources-basic facts and debates, NCCR Trade working paper No. 2011/67, Bern, Switzerland, 2011.

Cilliers, P., Biggs, H. C., Blignaut, S., Choles, A. G., Hofmeyr, J. S., Jewitt, G. P. W., and Roux, D. J.: Complexity, modeling, and natural resource management, Ecol. Soc., 18, 1, https://doi.org/10.5751/ES-05382-180301, 2013.

Cristofori, F., Issa, M., Yenikoye, A., Trucchi, G., Quaranta, G., Chanono, M., Semita, C., Marichatou, H., and Mattoni, M.: Artificial insemination using local cattle breeds in Niger, Trop. Anim. Health Pro., 37, 167-172, 2005.

Demeke, S., Neser, F. W. C., and Schoeman, J.: Estimates of genetic parameters for Boran, Friesian and crosses of Friesian and Jersey with Boran cattle in tropical highlands of Ethiopia: milk produc- tion traits and cow weight, J. Anim. Breed. Genet., 121, 163-175, https://doi.org/10.1111/j.1439-0388.2004.00446.x, 2004.

FAO: The Second Report on the State of the World's Animal Genetic Resources for Food and Agriculture, FAO, Rome, Italy, available at: http://www.fao.org/3/a-i4787e.pdf, 2015.

Hamadou, I., Moula, N., Siddo, S., Issa, M., Marichatou, H., Leroy, P., and Antoine-Moussiaux, N.: Mapping stakeholder viewpoints in biodiversity management: an application in Niger using Q methodology, Biodiv. Conserv., 25, 1973-1986, https://doi.org/10.1007/s10531-016-1175-x, 2016.

Halbleib, M. L. and Jepson, P. C.: Adapting an outcome-based education development process to meet near real-time challenges to sustainable agricultural production, J. Agr. Educ. Ext., 21, 109126, https://doi.org/10.1080/1389224X.2014.927377, 2015.

Issa, M., Semita, C., Marichatou, H., Nervo, T., Yenikoye, A., Cristofori, F., and Trucchi, G.: Comparative study of two methods of induction of estrus and fertility following artificial insemination in Azawak zebu in Niger, J. Life Sci., 7, 527-531, 2013.

Karugia, T. J., Okeyo, A. M., Kaitho, R., Drucker, A. G., Wollny, C. B. A., and Rege, J. O. E.: Economic analysis of crossbreeding programs in Sub-Saharan Africa: a conceptual framework and Kenyan case study, available at: http://citeseerx.ist.psu.edu/viewdoc/download?doi=10.1. 1.203.5524\&rep=rep1\&type $=$ pdf, 2001.

Klerkx, L., Van Mierlo, B., and Cees, L.: Evolution of systems approaches to agricultural innovation: concepts, analysis and interventions, in: Farming systems research into the 21st century: the new dynamic, Springer Science Business Media, Dordrecht, Netherlands, 457-483, 2012.

Kosgey, I. S., Baker, R. L., Udo, H. M. J., and Van Arendonk, J. A. M.: Successes and failures of small ruminant breeding programmes in the tropics: a review, Small Ruminant Res., 61, 13-28, 2006.

Lazard, L., Capdevila, R., and Roberts, A.: Methodological pluralism in theory and in practice: the case for $\mathrm{Q}$ in the community, Qual. Res. Psychol., 8, 140-150, https://doi.org/10.1080/14780887.2011.572749, 2011.

Leroy, G., Baumung, R., Boettcher, P., Scherf, B., and Hoffmann, I.: Review: sustainability of crossbreeding in developing countries, definitely not like crossing a meadow, Animal, 10, 262-273, https://doi.org/10.1017/S175173111500213X, 2015.

Leroy, G., Baumung, R., Boettcher, P., Scherf, B., and Hoffmann, I.: Review: sustainability of crossbreeding in developing countries, definitely not like crossing a meadow, Animal, 10, 262273, 2016.

Leroy, G., Baumung, R., Notter, D., Verrier, E., Wurzinger, M., and Scherf, B.: Stakeholder involvement and the management of animal genetic resources across the world, Livest. Sci., 198, 120 128, https://doi.org/10.1016/j.livsci.2017.02.018, 2017.

Madalena, F., Agyemang, K., Cardellino, R., and Jain, G.: Genetic improvement in medium-to low-input systems of animal production: experiences to date, 7th World Congress on Genetics Applied to Livestock Production, Montpellier, France, 19-23 August 2002, Communication No. 25-08, 2002.

Madan, M. L.: Animal biotechnology: application and economic implications in developing countries, Rev. Sci. Tech. OIE, 24, 127-139, 2005. 
McDonough, C., Nuberg, I. K., and Pitchford, W. S.: Barriers to participatory extension in Egypt: agricultural workers' perspectives. J. Agr. Educ. Ext., 21, 159-176, 2015.

MRA (Ministère des Ressources Animales): Document cadre de relance pour le secteur de l'élevage: état des lieux, axes d'intervention et programmes prioritaires, Ministère des Ressources Animales, Niamey, Niger, 2001.

MRA: Document cadre de relance pour le secteur de l'élevage: état des lieux, axes d'interventions et programmes prioritaires, Ministère des Ressources Animales, Niamey, Niger, 122 pp., 2003.

Ndahi, M. D., Kwaghe, V. A., Usman, J. G., Anzaku, S., Bulus, A., and Angbashim, J.: Detection of transboundary animal diseases using participatory disease surveillance in Plateau State, Nigeria, World Rural Observ., 4, 71-77, 2012.

Pereira, M. A., Fairweather, J. R., Woodford, K. B., and Nuthall, P. L.: Assessing the diversity of values and goals amongst Brazilian commercial-scale progressive beef farmers using Q-methodology, Agr. Syst., 144, 1-8, https://doi.org/10.1016/j.agsy.2016.01.004, 2016.

R Development Core Team R: A Language and Environment for Statistical Computing, R Foundation for Statistical Computing, Vienna, Austria, 2015.

Rege, J. E. O., Marshall, K., Notenbaert, A., Ojango, J. M. K., and Okeyo, A. M.: Pro-poor animal improvement and breeding - What can science do?, Livest. Sci., 136, 15-28, https://doi.org/10.1016/j.livsci.2010.09.003, 2011.

Scholtz, M. M., McManus, C., Okeyo, A. M., and Theunissen, A.: Opportunities for beef production in developing countries of the Southern Hemisphere, Livest. Sci., 142, 195-202, https://doi.org/10.1016/j.livsci.2011.07.014, 2011.

SDDE (Stratégie de développement durable de l'élevage): Stratégie de développement durable de l'élevage de 2013 à 2035, Ministère de l'Elevage, Niamey, Niger, 2013.
Shabila, N. P., AI-Tawil, N. G., AI-Hadithi, T. S., and Sondorp, E.: Using Q methodology to explore people's health seeking behavior and perception of the quality of primary care services, BMC Public Health, 14, 1-9, 2014.

Shiferaw, T. J., Mores, K., and Manyahilishal, K. E.: Participatory appraisal of foot and mouth disease in the Afar pastoral area, northeast Ethiopia: implications for understanding disease ecology and control strategy, Trop. Anim. Health Pro., 42, 193-201, https://doi.org/10.1007/s11250-009-9405-9, 2010.

Tisdell, C.: Socioeconomic causes of loss of animal genetic diversity analysis and assessment, Ecol. Econ., 45, 365-376, https://doi.org/10.1016/S0921-8009(03)00091-0, 2003.

Van Exel, N. J. A. and De Graaf, G.: Q methodology: a sneak preview, http://www.jobvanexel.nl/ (last access: 1 November 2017), 2005.

Vias, G.: Etude relative à la formulation du programme d'actions détaillé de développement de la filière lait en zone UEMOA, Annexe 6: rapport Niger, CIRAD, Montpellier, France, 2013.

Wenger, E.: Conceptual tools for CoPs as social learning systems boundaries, identity, trajectories and participation, in: Social learning systems and communities of practice, Springer, London, UK, 125-143, 2010.

World Bank: Agricultural Education and Training to Support Agricultural Innovation Systems, The World Bank, Washington DC, USA, 2012.

Yigrem, S., Beyene, F., Tegegne, A., and Gebremedhin, B.: Dairy production, processing and marketing systems of ShasemeneDilla area, south Ethiopia, Improving Productivity and Market Success of Ethiopian Farms Project, working paper 9, ILRI, Nairobi, Kenya, 2008.

Zabala, A.: Q method: a package to explore Human Perspectives using Q methodology, R J., 6, 163-173, 2014. 